NBER WORKING PAPER SERIES

\title{
AN EVALUATION OF INSTRUMENTAL VARIABLE STRATEGIES FOR ESTIMATING THE EFFECTS OF CATHOLIC SCHOOLS
}

\author{
Joseph G. Altonji \\ Todd E. Elder \\ Christopher R. Taber \\ Working Paper 9358 \\ http://www.nber.org/papers/w9358 \\ NATIONAL BUREAU OF ECONOMIC RESEARCH
1050 Massachusetts Avenue
Cambridge, MA 02138 \\ November 2002
}

This research was supported by the Institute for Policy Research, Northwestern University, the National Science Foundation under grant SBR 9512009, and the NIH-NICHD under grant R01 HD36480-03. We are grateful to Timothy Donohue for excellent research assistance and to Jeffrey Grogger, Derek Neal, and participants in seminars at Boston College, Northwestern University, University College London, University of Virginia, and University of Wisconsin for helpful comments. We are responsible for the remaining shortcomings of the paper. The views expressed herein are those of the authors and not necessarily those of the National Bureau of Economic Research.

(C) 2002 by Joseph Altonji, Todd Elder, and Christopher Taber. All rights reserved. Short sections of text, not to exceed two paragraphs, may be quoted without explicit permission provided that full credit, including (C) notice, is given to the source. 
An Evaluation of Instrumental Variable Strategies for Estimating the Effects of Catholic Schools

Joseph Altonji, Todd Elder, and Christopher Taber

NBER Working Paper No. 9358

November 2002

JEL No. I2, C2

\section{ABSTRACT}

Several previous studies have relied on religious affiliation and the proximity to Catholic schools as exogenous sources of variation for identifying the effect of Catholic schooling on a wide variety of outcomes. Using three separate approaches, we examine the validity of these instrumental variables. We find that none of the candidate instruments is a useful source of identification of the Catholic school effect, at least in currently available data sets

Joseph G. Altonji

Yale University

Economic Growth Center

27 Hillhouse Avenue

P.O. Box 208269

New Haven, CT 06520-8269

and NBER

joseph.altonji@yale.edu

Christopher R. Taber

Department of Economics

Northwestern University

Evanston, IL 60208

and NBER

ctaber@northwestern.edu
Todd E. Elder

Institute of Labor and Industrial Relations

University of Illinois at Urbana-Champaign

213 ILIR Building

504 East Armory Avenue

Champaign, IL 61822 


\section{Introduction}

The question of whether private schools provide better education than public schools is at the center of the current national debate over the role of vouchers, charter schools, and other reforms that increase choice in education. Since Catholic schools account for about two thirds of private school enrollment in the U.S., assessing the effectiveness of Catholic schools is an important part of the assessment of private schooling. This is especially true in light of a recent U.S. Supreme Court decision that permits students to use publicly financed vouchers to pay tuition at religious schools. Simple cross tabulations or multivariate regressions of outcomes such as high school graduation and college enrollment typically show a substantial positive effect of Catholic school attendance. However, the positive effects of Catholic school attendance may be due to nonrandom selection into Catholic schools that induces spurious correlations between Catholic school attendance and unmeasured family characteristics that are favorable to education.

All serious studies of public/private school differences acknowledge this sample selection problem and most wrestle with it in one way or another. ${ }^{1}$ In the absence of experimental data, the main option is to find a nonexperimental source of variation $Z_{i}$ in Catholic school attendance that is exogenous with respect to the outcome under study. The problem, however, is that most student background characteristics that influence schooling decisions, such as income, attitudes, and education of the parents, are likely to influence outcomes independently of the school since they are likely to be related to other parental inputs. These variables must be included in the vector of controls $X_{i}$ to avoid omitted variables bias. Characteristics of private and public schools such as tuition levels, student body characteristics, or school policies are likely to be related to the effectiveness of the schools and so are poor candidates for excluded instruments.

Two influential papers provide potential instrumental variables. Evans and Schwab (1995) treat Catholic schooling as exogenous in much of their analysis, but also present estimates that rely in part on the assumption that religious affiliation affects whether a person attends a Catholic school but has no independent effect on the outcome under study.

\footnotetext{
${ }^{1} \mathrm{~A}$ few examples of early studies of Catholic schools and other private schools are Coleman et al (1982), Noell (1982), Goldberger and Cain (1982), Alexander and Pallas (1985), and Coleman and Hoffer (1987). Recent studies include Evans and Schwab (1993,1995), Tyler (1994), Neal (1997), Figlio and Stone (1998), Grogger and Neal (2000), Sander (2001), and Jepsen (forthcoming). Murnane (1984), Witte (1992), Chubb and Moe (1990) and Cookson (1993), and Sander (2001) provide overviews of the discussion and references to the literature.
} 
Specifically they use a dummy variable for affiliation with the Catholic church $\left(C_{i}\right)$ as their excluded variable. Some support for this assumption is evidenced by the fact that being Catholic is strongly correlated with Catholic school attendance, while Catholics are not far from national averages on many socio-economic indicators. Evans and Schwab find a strong positive effect of Catholic school attendance on high school graduation and on the probability of starting college. However, as Murnane (1985), Tyler (1994), and Neal (1997) note, being Catholic could well be correlated with characteristics of the neighborhood and family that influence the effectiveness of schools. ${ }^{2}$

Neal (1997) uses proxies for geographic proximity to Catholic schools as an exogenous source of variation in Catholic high school attendance (see also Tyler, 1994). The basic assumption is that the location of Catholics or Catholic schools was determined by historical circumstances unrelated to unobservables that influence performance in schools. Using data from the National Longitudinal Survey of Youth (NLSY), Neal estimates bivariate probit models of Catholic high school attendance and high school graduation, in which Catholic school effects are identified by excluding whether the person is Catholic, the fraction of Catholics in the county population, and the number of Catholic schools in the county. ${ }^{3}$

The interaction between whether a person is Catholic and the availability of Catholic schools is a natural alternative to using distance or religion separately. It is quite possible that proximity to Catholic schools is related to differences in regional and family characteristics that have a direct influence on schooling and labor market outcomes, given that Catholic schools are somewhat concentrated by region. ${ }^{4}$ However, since "tastes" for Catholic schooling

\footnotetext{
${ }^{2}$ Neal (1997) points out that one problem with using $C_{i}$ as an instrumental variable when estimating Catholic school effects (as in Neal (1997) and Evans and Schwab (1995)) is that religious identification might be influenced by the school type attended. Neither study investigates the issue. In the case of NELS:88 we use the parent's report of religious affiliation while the student is in eighth grade as our religion measure. Cross tabulations of differences between the parent's report and the child's tenth grade report with whether the child attends a Catholic high school suggest that attending a Catholic high school influences the child's report. However, our NELS:88 results are not very sensitive to using the child's report in place of the parent's eighth grade report. Consequently, our evidence on the importance of this issue is mixed.

${ }^{3}$ His results are not sensitive to adding Catholic to the outcome equation. However, in the appendix we show that in our data nonlinearities in the effects of religion and family background rather than the location variables are the main source of identification when we use Neal's measures of proximity to Catholic schools. Tyler (1994) uses the fraction of students in the school district who attended Catholic schools as an instrument. However, Tyler does not allow this variable or other detailed geographic variables to have a direct effect on the outcome. Tyler notes that his aggregated measure of school choice is likely to be affected by district level variation in family or school characteristics that affect outcomes as well as by distance to Catholic schools. For both reasons, his results should be discounted.

${ }^{4}$ Hoxby (1995) discusses geographical concentration by region, much of which is associated with the geographic concentration of the Catholic population in the past.
} 
depend strongly on religious preference, the interaction between distance $\left(D_{i}\right)$ and religious affiliation will have an effect on Catholic school attendance that is independent of the separate effects of religious affiliation and distance. In particular, Catholic school attendance is likely to be much more sensitive to distance for Catholics than for non-Catholics. Consequently, one can control for both religious affiliation and for distance from Catholic schools, as well as for a set of other geographic characteristics (such as city size, region, labor market characteristics, average family income, and public school characteristics), while excluding the interaction $C_{i} \times D_{i}$ from outcome models. However, the case that $C_{i} \times D_{i}$ may be a valid instrument even if $C_{i}$ and $D_{i}$ are not is far from bulletproof. Catholic parents who want their children to attend Catholic schools might choose to live near Catholic schools. This could lead to a positive or negative bias depending on the relationship between preferences for Catholic school and the error component in the outcome equation. Also, past immigration patterns and internal migration from city to suburb and across regions may have led to differences between Catholics and non-Catholics in the correlation between proximity to Catholic schools and observed and unobserved components of family background.

In this paper we explore the validity of $C_{i}, D_{i}$, and $C_{i} \times D_{i}$ as exogenous sources of variation for identifying the effects of Catholic schooling on educational attainment and achievement. Religion and proximity have figured prominently in the literature regarding Catholic schools, but there is a need for a systematic effort to evaluate these measures as valid instrumental variables. We use multiple data sets and methods to perform such an evaluation. Our main data set is the National Educational Longitudinal Survey of 1988 (NELS:88), but we also report results based on the National Longitudinal Study of the High School Class of 1972 (NLS-72). For each instrument, we present 2SLS and bivariate probit estimates that rely on the particular instrument as the source of identification and compare the results to OLS and univariate probit estimates.

In addition to examining the a priori case for the instruments, the face plausibility and precision of the IV estimates, and the consistency across data sets, we assess the quality of the instruments in two other ways. The first approach takes advantage of the fact that few students who attend public 8th grades attend Catholic high school. This provides some justification for using the coefficient on the instrument in a reduced-form outcome equation from a sample of public eighth grade attendees in NELS:88 as an estimate of the direct link between Catholic religion and the outcome. 
The second approach uses a methodology introduced in Altonji, Elder and Taber (2001) (hereafter, AET) to assess the instrumental variable results. AET's approach is based on the idea of using the degree of selection on observables as a guide to how much selection there is on unobservables. ${ }^{5}$ In an ideal world, the instrument would be randomly assigned either by nature or through a controlled experiment. In this case, the instruments would be uncorrelated with both the observed and unobserved determinants of the outcome. Short of that, the hope in using an IV strategy is that the observed variables that are used as controls in the outcome equation are systematically chosen so that the instrumental variable has no relationship with the unobserved variables that determine the outcome, conditional on the observables. However, as AET argue, major data sets with large samples and extensive questionnaires are not designed to address one relatively specific question, such as the effectiveness of Catholic schools using a particular IV approach, but rather to serve multiple purposes. Because there are a limited number of factors that we know how to collect, can afford to collect, and expect to matter for a particular outcome, many relevant variables are left out. In such a world, it is prudent to consider an alterative benchmark case in which the observed variables are a random subset of the factors that influence the outcome rather than the perfect control set given the instrument. This is particularly true in the absence of strong prior information about the sources of variation in the instrument. AET show that under certain conditions, the regression coefficients relating the instrumental variable to the regression index of the observables in the outcome equation and to the error term in the outcome equation will be the same. We use their approach to estimate what the bias in the IV estimates would be if the assumption of equal selection on observables and unobservables were correct. We restrict ourselves to NELS:88 because the calculation only makes sense when a rich set of observables is available.

We began our study with the strong prior that the reliance on the interaction between distance from Catholic schools and Catholic religion to identify the Catholic school effect could overcome potential objections to the exclusion of location variables and religion from the outcome equations, thereby providing convincing estimates of the Catholic school effect. Unfortunately, we end it with the negative conclusion that distance, religion, and distance

\footnotetext{
${ }^{5}$ Researchers often informally argue for the exogeneity of membership in a "treatment group" or of an instrumental variable by examining the relationship between group membership or the instrumental variable and a set of observed characteristics, or by assessing whether point estimates are sensitive to the inclusion of additional control variables. See for example, Currie and Duncan (1995), Engen et al (1996), Poterba et al (1994), Angrist and Evans (1998), Jacobsen et al. (1999), Bronars and Grogger (1994), and Udry (1998).
} 
interacted with religion are all problematic instrumental variables, at least in the existing national data sets.

In Section 2 we discuss the data from NLS-72 and NELS:88 that are used in the study. In Section 3 we present results using religion as the source of identification and provide some initial evidence on the direct effect of being Catholic on educational attainment. We also introduce and apply AET's method of using the observables to assess the potential for bias from an association between the instrument and the unobservables. In Section 4 and in Section 5 we present results using distance and the interaction between distance and religion as the excluded instruments. Section 6 concludes.

\section{Data}

\subsection{NELS:88}

NELS:88 is a National Center for Education Statistics (NCES) survey which began in the Spring of 1988. The base year sample is a two stage stratified probability sample in which a set of schools containing eighth grades were chosen on the basis of school size and private/public status. In the second stage, as many as 26 eighth grade students from within a particular school were chosen based on race and gender. A total of 1032 schools contributed student data in the base year survey, resulting in 24,599 eighth graders participating. Subsamples of these individuals were reinterviewed in 1990, 1992, and 1994. The NCES only attempted to contact 20,062 base-year respondents in the first and second follow-ups, and only 14,041 in the 1994 survey. Additional observations are lost due to attrition.

Parent, student, and teacher surveys in the base year provide a rich set of information on family and individual background, as well as pre-high school achievement, behavior, and expectations of success in high school and beyond. Each student was also administered a series of cognitive tests in the 1988, 1990, and 1992 surveys to ascertain aptitude and achievement in math, science, reading, and history. We use standardized item response theory (IRT) test scores that account for the fact that the difficulty of the 10th and 12th grade tests taken by a student depends on the 8th grade scores. We use the 8th grade test scores as control variables and the 10 th and 12 th grade reading and math tests as outcome measures.

For each respondent, a measure of distance from the nearest Catholic high school was

obtained by computing the distance from the zip code centroid of the respondent's eighth 
grade school to the zip code centroid of the closest Catholic high school ${ }^{6}$. From this information we constructed our distance measure $D_{i}$, which is a vector of mutually exclusive indicators for distance less than 1 mile, 1 to 3 miles, 3 to 6 miles, 6 to 12 miles, and 12 to 20 miles, with greater than 20 miles treated as the omitted category. Our religion indicator $C_{i}$ is 1 if parents indicated that they are Catholic in response to a question about religious affiliation in the base year survey and is 0 otherwise.

Our main outcome measures are high school graduation $\left(H S_{i}\right)$ and college attendance $\left(C O L L_{i}\right) . \quad H S_{i}$ is one if the respondent graduated high school by the date of the 1994 survey, and zero otherwise. ${ }^{7} C O L L_{i}$ is one if the respondent was enrolled in a four-year university at the date of the 1994 survey and zero otherwise. ${ }^{8}$ The indicator variable for Catholic high school attendance, $\mathrm{CH}_{i}$, equals one if the current or last school in which the respondent was enrolled was Catholic as of 1990 (two years after the eighth grade year) and zero otherwise. ${ }^{9}$ Unless noted otherwise, the results reported in the paper are weighted. ${ }^{10}$

\section{$2.2 \quad$ NLS-72}

The NLS-72 is a Department of Education survey of high school students that contains information on 22,652 persons who were seniors during the 1971-1972 academic year. Additional interviews were conducted in 1973, 1974, 1976, 1979, and 1986. The final sample sizes are 19,489 students from 1192 public high schools and 71 Catholic high schools for the college attendance indicator variable, 14,671 students from 879 public high schools and 57 Catholic

\footnotetext{
${ }^{6}$ Detailed information on zip code characteristics of the eighth grade school (at the zip code level) is available on the NELS:88 Restricted Use files. For the NELS:88 analysis, the zip code of every Catholic high school in the United States in 1988 was obtained from Ganley's Catholic High Schools in America: 1988. The distance from a particular zip code centroid to the centroids of all the catholic high schools was calculated using an algorithm obtained from the U.S. National Oceanic and Atmospheric Administration.

${ }^{7}$ We obtain similar results using a "drop out" dummy variable which equals one if a student dropped out of high school by 1992, or if the student dropped out of high school by 1990 and was not reinterviewed in 1992 or 1994, zero otherwise. This variable catches dropouts who left the survey by 1990 and were either dropped from the sample or were nonrespondents.

${ }^{8}$ Our major findings are robust to whether or not college attendance is limited to 4-year universities, full-time versus part-time, or enrolled in college "at some time since high school" or at the survey date.

${ }^{9} \mathrm{~A}$ student who started in a Catholic high school and transferred to a public school prior to the tenth grade survey would be coded as attending a public high school $(\mathrm{CH}=0)$. If such transfers are frequently motivated by discipline problems, poor performance, or alienation from school, then misclassification of the transfers as public high school students could lead to upward bias in estimates of the effect of $C H$ on educational attainment. AET present evidence that this issue is of minor importance.

${ }^{10}$ The sampling scheme in the NELS:88 is complicated and explained in more detail in AET (2002). The results are somewhat sensitive to the use of sample weights, although our main findings are robust to weighting. Given the sampling scheme the weighted estimates are clearly preferred.
} 
high schools for the math and reading score variables, and 16,276 students from 1191 public high schools and 71 Catholic high schools for the years of academic education variable. ${ }^{11}$

The variable $C_{i}$ is 1 for students who indicated they were Catholic in response to a base year question about religious affiliation and is 0 otherwise. Distance from the nearest Catholic high school was recorded as the distance in air miles between the centroids of the zip code of residence reported in the first follow-up, and the zip code of the nearest Catholic high school. ${ }^{12}$ The follow-up survey included an indicator for whether the respondent had moved between their senior year of high school and the survey date, so the 10,530 students who moved were assigned the mean value of distance for all non-movers who attended the same high school. ${ }^{13}$

In the original design, schools with a high percentage of minority students and in low income areas are overrepresented, and sampling weights also vary with whether the school is public or private. The results are not sensitive to weighting procedures, so the estimates reported below are based on unweighted data.

\section{Using Religious Affiliation to Identify the Catholic School Effect}

In Table 1, we present univariate probit, OLS, bivariate probit, and 2SLS estimates of the Catholic school effect for our three separate instrumental variables. The table footnotes provide a list of the family background, city size, region, student characteristics, and eighthgrade behavioral and academic outcomes that are included in both the equations for $\mathrm{CH}_{i}$ and the outcomes $\left(Y_{i}\right)$. In this section our focus is on the first column in which we use $C_{i}$ as the excluded instrument and include $D_{i}$ but not $C_{i} \times D_{i}$ in the equations for both $C H_{i}$ and $Y_{i}$. In sections 4 and 5 we will discuss the results from the second and third column, respectively.

\footnotetext{
${ }^{11}$ The 2236 students who did not report their religious affiliation are excluded from the analysis. We also drop an additional 495 students for whom we could not impute distance from the nearest Catholic high school, reducing the sample size to 19,921. We also exclude 111 cases in which the student attended a non-Catholic private school, and additional observations are lost because data for key control variables and outcomes are missing.

${ }^{12}$ The zip code of every Catholic high school in existence in the United States is listed in the US Department of Education's "Universe of Private Schools".

${ }^{13}$ The 495 students who were dropped because no distance measures could be created for them either attended one of the 26 high schools for which there are no valid observations on distance, or did not have valid values for the geographic move variable. These schools were part of NLS-72's "backup sample", and the students in this subsample were lost because they were excluded from the first follow-up.
} 
In NELS:88 the 2SLS estimate for high school graduation is 0.34 (0.08). This point estimate is extremely large, given that the sample mean of $H S_{i}$ is 0.84 . The bivariate probit estimate of the average marginal effect is a more reasonable value of 0.128 , but it is still double the univariate probit estimate. The estimates of the effect on enrollment in a four-year college in 1994 are also unreasonably large, as the 2SLS coefficient of 0.40 (0.10) is larger than the sample mean of 0.29. The bivariate probit estimate of 0.170 is also well above the univariate probit estimate of 0.094 .

We obtain a different pattern in NLS-72 (bottom panel). For this data set the analysis conditions on enrollment in 12th grade, so one should not expect these results to exactly mirror those in NELS:88. The probit estimate of the effect of $C H_{i}$ on college attendance is 0.068 , which is roughly equal to the two stage least squares estimate of $0.06(0.04)$. This apparent similarity should be interpreted carefully, as the 2SLS standard error is substantial. In fact, the point estimate is not significantly different from zero even though it implies a large Catholic schooling effect. ${ }^{14}$

The bivariate probit estimate is only -0.002 , but it should be kept in mind that the source of identification in the bivariate probit case is a complicated nonlinear function of the variables in the model for $C H_{i}$ and not simply $C_{i}$, even though only $C_{i}$ is excluded from the outcome equation. In particular, we suspect that the interaction between $C_{i}$ and $D_{i}$ plays an important role and leads to a reduction in the point estimate relative to 2SLS for reasons that will become clear when we discuss the results based on $C_{i} \times D_{i}$. We analyze the bivariate probit in the appendix and conclude that identification comes primarily from the functional form assumption rather than the exclusion restrictions. Thus we focus on the 2SLS results when thinking about the validity of particular instruments.

Table 2 reports OLS and two stage least square estimates of the effect of Catholic high school on test scores in NELS:88 and a variety of outcomes in NLS-72. Column (1) shows that the 2SLS estimates are larger for both NELS test scores than the single-equation ones, although the 2SLS coefficients are noisy. The standard deviation of these tests is 10, so the 2SLS estimate of 2.64 implies a large impact on 12th grade math scores. However, the fact that the OLS estimates are uniformly smaller indicates that either 2SLS is biased upward or that Catholic high school students are actually negatively selected on the basis

\footnotetext{
${ }^{14}$ The NELS:88 results change very little when we condition the analysis on making it to 12th grade or on $H S=1$, so we cannot attribute the similarity of the results from 2SLS and single-equation methods in NLS-72 but not NELS:88 to the fact that NLS-72 is limited to those who have made it to 12th grade.
} 
of unmeasured factors which are correlated with test scores. The NLS-72 test score results follow the opposite pattern-2SLS estimates are negative while OLS is large and positive for both reading and math. It should be kept in mind that the NLS-72 results do not control for eighth grade achievement.

To summarize, in NELS:88 the 2SLS estimates using $C_{i}$ as the exclusion restriction imply that the Catholic school effect is very large, particularly for educational attainment. The results based on NLS-72 are more mixed but are consistent with a substantial positive effect on educational attainment. One might be tempted to conclude that IV estimates, while unreasonably large, bolster the probit and OLS evidence that the true effect is substantial. In the remainder of this section, we explore whether this is the right interpretation.

\subsection{Comparing the Characteristics of Catholics and non-Catholics}

Column (1) of Table 3a presents sample means of a set of family background characteristics, student characteristics, eighth grade outcomes, and high school outcomes in NELS:88, and Column (2) shows the difference between Catholics and non-Catholics in these means. ${ }^{15}$ The table shows that Catholics are 7 percentage points more likely to graduate high school and 8 percentage points more likely to be enrolled in a four year college in 1994. Differences in tenth and twelfth grade test scores are more modest but all show a significant advantage for Catholic students. If Catholic was as good as randomly assigned, these differences would be entirely attributed to the fact that Catholics are more likely to attend Catholic high school. It would then be troubling if Catholic appeared to be related to variables determined prior to high school enrollment. Consequently, we begin our evaluation of Catholic religion as an excluded instrument by following the common practice of simply comparing the characteristics of Catholics and non-Catholics in both NELS:88 and NLS-72.

Unfortunately, differences by $C_{i}$ appear in many of the family and student characteristics and eighth grade outcomes in Table 3a. There is a modest positive association between Catholic religion and parental educational expectations, with a gap of 0.04 in the fraction of parents who expect their children to attend some college and 0.03 in the fraction who expect at least a college degree. ${ }^{16}$ While the differential in family income is positive, it is negative in

\footnotetext{
${ }^{15}$ In Table $3 a$ the outcome variables are weighted with the same weights used in the regression analysis, so that the 10th and 12th grade test scores are weighted using first and second follow-up panel weights, respectively, and high school graduation and college attendance are weighted by third follow-up weights. All other variables are weighted using second follow-up panel weights.

${ }^{16}$ Some of the variables used in our multivariate models are excluded from Table $3 a$ to keep them man-
} 
mother's and father's education. However, Table 3a also shows that Catholic students have favorable characteristics across a broad set of measures available in eighth grade, such as test scores, grades, and teacher evaluations of the student's behavior. Among these eighth grade variables, only the "unpreparedness index" variable does not vary favorably with $C_{i}$. The discrepancy in the fraction of students who repeated a grade in grades $4-8$ is -0.03 , and the gap in the fraction of students who are frequently disruptive is -0.02 . The existence of gaps in favor of Catholic students across several dimensions suggests that Catholic and non-Catholic students differ in many respects, some of which may be unobservable to empirical researchers. Since these differences also contribute to high school and post-high school outcomes (see AET for evidence), doubts arise regarding the validity of using $C_{i}$ as an instrumental variable for Catholic high school attendance.

In NLS-72, the differences are less pronounced, although it appears that overall Catholic religion has a weak positive association with favorable family background characteristics. Log family income is 0.07 higher for Catholics, who are also five percentage points less likely to be members of families which meet NLS-72's definition of low socio-economic status. There are also essentially no differences in parental education levels or pre-high school student educational expectations, with an insignificant negative gap of -0.01 (0.007) in an indicator for whether the student decided to attend college before high school.

Given the overall picture of Tables $3 \mathrm{a}$ and $3 \mathrm{~b}$, we anticipate that the use of $C_{i}$ as an instrumental variable will likely result in positively biased estimates of Catholic schooling effects in NELS:88, and perhaps a small positive bias in NLS-72, although it is difficult to gauge the extent of the bias. The richness of the NELS:88 data permits us to use two more formal procedures to gauge its magnitude and direction.

\subsection{The Effect of Catholic Religion for Students from Public Eighth Grades}

One way to assess the endogeneity of Catholic religion is to identify a sample of persons for whom Catholic high school is not a serious option, and then interpret the coefficient on $C_{i}$ in a single equation model as an estimate of the direct effect of Catholic religion on the outcome. Only $0.3 \%$ of public school eighth graders in our effective sample go on to attend Catholic high school; the percentage is $0.7 \%$ among public eighth grade attendees

ageable given sample sizes. The expectations variables in Table 3a are excluded from our outcome models because if Catholic school has an effect on outcomes, this may be influence expectations. 
whose parents are Catholic. For the moment we abstract from the fact that restricting the analysis to the public eighth-grade sample will induce some selection bias in estimates of the direct relationship between Catholic religion and the outcome. We argue at the end of the section that taking account of such selection bias strengthens the evidence against $C_{i}$ as an instrument.

To motivate the exercise in this section suppose that

$$
Y_{i}=\alpha C H_{i}+X_{i}^{\prime} \gamma+\varepsilon_{i}
$$

where $X_{i}$ is uncorrelated with $\varepsilon_{i}$. The problem is that $C H_{i}$ and potentially $C_{i}$ may be correlated with the error term. If we estimate $\alpha$ by 2SLS using $C_{i}$ as an instrument for $C H_{i}$ the bias is

$$
\begin{aligned}
2 S L S \text { bias } & =\frac{\operatorname{Cov}\left(\widetilde{C}_{i}, \varepsilon_{i}\right)}{\lambda \operatorname{Var}\left(\widetilde{C}_{i}\right)} \\
& =\frac{\phi}{\lambda}
\end{aligned}
$$

where $\widetilde{C}_{i}$ are the residuals of a regression of $C_{i}$ on $X_{i}, \phi$ is $\frac{\operatorname{Cov}\left(\widetilde{C}_{i}, \varepsilon_{i}\right)}{\operatorname{Var}\left(\widetilde{C}_{i}\right)}$, and $\lambda$ is the probability limit of the coefficient on $C_{i}$ from the first stage regression. Now suppose there is an event $p_{i}$ on which we can condition for which $\operatorname{Pr}\left(C H_{i}=1 \mid p_{i}\right)=0$. In our application this event is attendance of a public eighth grade by individual $i$. Assume that the joint distribution of $\left(X_{i}, C_{i}, \varepsilon_{i}\right)$ is independent of $p_{i}$. Consider a regression of $Y_{i}$ on $X_{i}$ and $C_{i}$ conditional on $p_{i}$. Under these conditions, the coefficient on $C_{i}$ in (1) will converge to $\phi$. Since we have a consistent estimate of $\lambda$ from the first stage regression, we can obtain a consistent estimate of the bias $\psi$ by taking the ratio $\phi / \lambda$ or by estimating the parameter $\psi$ in the regression model

$$
Y_{i}=X_{i}^{\prime} \gamma+\left[C_{i} \widehat{\lambda}\right] \psi+\omega_{i}
$$

on the public eighth grade sample.

In column 1 of Table 4 we report estimates of the bias parameter $\psi$ using this approach. ${ }^{17}$ We present separate equations estimated for $H S_{i}, C O L L_{i}$, and the 12 th grade math and reading test scores. The vector $X_{i}$ includes all of the other controls that were included

\footnotetext{
${ }^{17}$ Eliminating the 36 students who attended public 8 th grade and went on to Catholic high school has little effect on the results.
} 
in our models in Tables 1 and 2. For ease of comparison, the table also presents the corresponding 2SLS estimates from Table 1 and 2.

The results are striking-the implied bias in the 2SLS estimate is $0.34(0.08)$ for $H S_{i}$, which is identical to the 2SLS coefficient itself. $^{18}$ The large potential bias should raise a great deal of concern about using Catholic as an instrument, particularly given the remarkable similarity between the magnitudes of the bias and the 2SLS estimate. In our view, this evidence alone is sufficient to rule out $C_{i}$ as a useful instrument.

In the college attendance case the (unreported) estimate of $\phi$ is 0.038 (0.013). Catholic students are nearly four percentage points more likely to enroll in a four year college than nonCatholics even when Catholic high school is not a serious option. This relationship implies a bias of $0.29(0.11)$ in 2SLS estimates, so it seems likely that the large 2SLS estimates in Table 1 result from the endogeneity of $C_{i}$ with respect to both high school graduation and college attendance. Similar calculations imply that the math test score estimate from Table 2 can largely be explained by potential bias of 1.85 (1.41) for the 12 th grade math scores. Part of the college attendance and test score effects may be "real," as these large corrections are still smaller than the 2SLS point estimates, but the substantial evidence of endogeneity of $C_{i}$ combined with the imprecision of the estimates prevents any firm conclusions about the effect of Catholic high school on these outcomes.

We now return to the selection problem induced by focusing only on public eighth graders. The analysis in this section has treated public eighth grade attendance as if it were randomly assigned. We typically would expect positive selection of Catholics into Catholic grade schools. That is, Catholic students who attend Catholic grade schools are likely to have higher values of $\varepsilon_{i}$ in equation (1) than Catholic public school students. Since non-Catholics are much less likely to attend Catholic schools this effect will lead to a negative bias in $\operatorname{Cov}\left(\widetilde{C}_{i}, \varepsilon_{i}\right)$ when we condition on public school attendance. ${ }^{19}$ This would imply that our estimates of $\phi / \lambda$ are biased downward, which makes the results in this section even more surprising.

\footnotetext{
${ }^{18}$ To see how we arrive at this figure, note that the estimate of $\phi$ in the $H S$ equation is $0.044(0.011)$. That is, the graduation probability among students who go to public eighth grade is estimated to be 0.044 higher for Catholics than non-Catholics, even though hardly any of these students attend Catholic high schools. Since $\lambda$ is estimated to be $0.130(0.009)$, the bias is approximately $0.34(=0.044 / 0.130)$.

${ }^{19}$ To see this in a simple case, abstract from observables so that $\widetilde{C}_{i}=C_{i}$, and assume that non-Catholics do not attend Catholic schools, that $E\left(\varepsilon_{i} \mid C_{i}\right)=0$ unconditional on $p_{i}$, and that there is positive selection into Catholic eighth grades so that $E\left(\varepsilon_{i} \mid C_{i}=1, p_{i}^{c}\right)>E\left(\varepsilon_{i} \mid C_{i}=1, p_{i}\right)$, where $p_{i}^{c}$ is the complement of $p_{i}$. This implies that $E\left(\varepsilon_{i} \mid C_{i}=1, p_{i}\right)<0$ and thus the bias is negative.
} 


\subsection{Using the Observables to Assess the Bias from Unobservables}

In this section we extend the methodology of AET to assess the potential bias in the instrumental variables estimates. For simplicity we focus on the linear case when illustrating the procedure although the methods are also applicable to non-linear models.

Let the outcome $Y_{i}$ be again determined by

$$
Y_{i}=\alpha C H_{i}+X_{i}^{\prime} \gamma+\varepsilon_{i}
$$

where $\gamma$ is defined so that $\operatorname{cov}\left(\varepsilon_{i}, X_{i}\right)=0$.

$\mathrm{CH}_{i}$ is potentially endogenous and thus correlated with $\varepsilon_{i}$. We assume that our instrument $Z_{i}$ does not influence $Y_{i}$ directly, but is correlated with $C H_{i}$. However, $Z_{i}$ is not necessarily a valid instrument because it may be correlated with $\varepsilon_{i}$.

Define $\beta, \pi$, and $\lambda$ to be the coefficients of the least squares projections

$$
\begin{aligned}
\operatorname{Proj}\left(Z_{i} \mid X_{i}\right) & =X_{i}^{\prime} \pi \\
\operatorname{Proj}\left(C H_{i} \mid X_{i}, Z_{i}\right) & =X_{i}^{\prime} \beta+\lambda Z_{i} .
\end{aligned}
$$

Define $v_{i}$ and $u_{i}$ as the residuals of these projections, so that

$$
\begin{aligned}
v_{i} & \equiv Z_{i}-X_{i}^{\prime} \pi \\
u_{i} & \equiv C H_{i}-X_{i}^{\prime} \beta-\lambda Z_{i} .
\end{aligned}
$$

and note that $v_{i}$ and $u_{i}$ are orthogonal to $X_{i}$ by construction. Consider the regression of $Y_{i}$ on $\left(X_{i}^{\prime} \beta+\lambda Z_{i}\right)$ and $X_{i}$. The coefficient on $\left(X_{i}^{\prime} \beta+\lambda Z_{i}\right)$ in this regression converges to

$$
\widehat{\alpha}=\alpha+\frac{\operatorname{cov}\left(v_{i}, \varepsilon_{i}\right)}{\lambda \operatorname{var}\left(v_{i}\right)} .
$$

One can see from (8) that the crucial assumption justifying the validity of $Z_{i}$ as an instrument is that

$$
\operatorname{cov}\left(v_{i}, \varepsilon_{i}\right)=0
$$

Under this condition, $2 S L S$ yields a consistent estimate of $\alpha$.

In contrast we consider the case in which $Z_{i}$ is not a valid instrument and the researcher does not have a strong prior about how it is determined. In particular, rather than assume 
that the choice of $X_{i}$ ensures that $v_{i}$ is uncorrelated with $\varepsilon_{i}$, assume that $X_{i}$ is random subset of all of the factors that determine $Y_{i}$ in addition to $\mathrm{CH}_{i}$. In AET we derive Condition 1-IV (not shown), as an alternative to the assumption $\operatorname{cov}\left(v_{i}, \varepsilon_{i}\right)=0$. Condition 1-IV says that the effect on $Z_{i}$ of a unit change in the index of observables that determine $Y_{i}$ and the index of unobservables is the same. The condition can be written as

$$
\frac{\operatorname{cov}\left(v_{i}, \varepsilon_{i}\right)}{\operatorname{var}\left(\varepsilon_{i}\right)}=\frac{\operatorname{cov}\left(X_{i}^{\prime} \pi, X_{i}^{\prime} \gamma\right)}{\operatorname{var}\left(X_{i}^{\prime} \gamma\right)}
$$

Describing the assumptions that lead to (10) requires that we introduce more of the notation from AET. Let the outcome $Y_{i}$ be determined as

$$
\begin{aligned}
Y_{i} & =\alpha C H_{i}+W_{i}^{\prime} \Gamma \\
& =\alpha C H_{i}+X_{i}^{\prime} \Gamma_{X}+\xi_{i}
\end{aligned}
$$

where $W_{i}$ is the vector of characteristics (observed and unobserved) that fully determine $Y_{i}$ and $\Gamma$ is the causal effect of $W_{i}$ on $Y_{i}$. In the second part of the equation $X$ is the vector of observed variables, $\Gamma_{X}$ is the corresponding subvector of $\Gamma$, and the error component $\xi_{i}$ is an index of the unobserved variables. Because it is extremely unlikely that the control variables $X_{i}$ are all unrelated to $\xi_{i}$, we work with (3) where $\gamma$ is defined so that $\operatorname{cov}\left(\varepsilon_{i}, X_{i}\right)=0 .{ }^{20}$

The precise conditions that imply Condition 1-IV are given in AET, but basically it requires the following three types of assumptions:

1. the elements of $X_{i}$ are chosen at random from the full set of factors $W_{i}$ that determine $Y_{i}$

2. the number of elements in $X_{i}$ and $W_{i}$ is large, and none of the factors dominates the distribution of the instrument $Z_{i}$ or the outcome $Y_{i}$,

3. the relationship between the observable elements $X_{i}$ and the unobservables obeys a very strong assumption that is similar to, but weaker than the standard assumption $\operatorname{cov}\left(X_{i}, \xi_{i}\right)=0$ that is maintained when applying instrumental variables estimators. ${ }^{21}$

\footnotetext{
${ }^{20}$ Consequently, $\gamma$ captures both the direct effect of $X_{i}$ on $Y_{i}^{*}, \Gamma_{X}$, as well as the relationship between $X_{i}$ and the mean of $\xi_{i}$. Note that $W_{i}^{\prime} \Gamma=X_{i}^{\prime} \Gamma_{X}+\xi_{i}=X_{i}^{\prime} \gamma+\varepsilon_{i}$.

${ }^{21}$ Mean independence of $\xi_{i}$ and $X_{i}$ is maintained in virtually all studies of selection problems, because without it, $\alpha$ is not identified even if one has a valid exclusion restriction (the exception is when the instrument
} 
Under these assumptions the relationship between the indices of observables in the equation for $Z_{i}$ and the outcome equation will be the same as the relationship between the indices of unobservables in the two equations, as implied by (10).

In the case in which $Z_{i}$ is an indicator variable such as $C_{i},(10)$ can be rewritten as

$$
\frac{E\left(\varepsilon_{i} \mid Z_{i}=1\right)-E\left(\varepsilon_{i} \mid Z_{i}=0\right)}{\operatorname{Var}\left(\varepsilon_{i}\right)}=\frac{E\left(X_{i}^{\prime} \gamma \mid Z_{i}=1\right)-E\left(X_{i}^{\prime} \gamma \mid Z_{i}=0\right)}{\operatorname{Var}\left(X_{i}^{\prime} \gamma\right)}
$$

The term $\frac{E\left(X_{i}^{\prime} \gamma \mid Z_{i}=1\right)-E\left(X_{i}^{\prime} \gamma \mid Z_{i}=0\right)}{\operatorname{Var}\left(X_{i}^{\prime} \gamma\right)}$ is the normalized shift in the index of observables in the outcome equation that is associated with $Z_{i}$, while the term $\frac{E\left(\varepsilon_{i} \mid Z_{i}=1\right)-E\left(\varepsilon_{i} \mid Z_{i}=0\right)}{\operatorname{Var}\left(\varepsilon_{i}\right)}$ is the corresponding normalized shift in the distribution of unobservables. This is a formalization of the common practice of checking for a systematic relationship between an instrumental variable and the mean of the elements of $X_{i}$. Intuitively, if one estimates $\frac{E\left(X_{i}^{\prime} \gamma \mid Z_{i}=1\right)-E\left(X_{i}^{\prime} \gamma \mid Z_{i}=0\right)}{\operatorname{Var}\left(X_{i}^{\prime} \gamma\right)}$ and finds that it is substantially different from zero, one may be worried that the null hypothesis $E\left(\varepsilon_{i} \mid Z_{i}\right)=0$ is wrong.

We can use (11) to approximate the amount of bias in 2SLS estimates of Catholic schooling effects if selection on unobservables is similar to selection on observables. Combining

is uncorrelated with $X_{i}$ as well as $\varepsilon_{i}$, as when the instrument is randomly assigned in an experiment). If the observables are correlated with one another, as in most applications, then the observed and unobserved determinants of $Y_{i}$ are also likely to be correlated.

Assume that the conditional expectation is linear. Following the notation above, define $\gamma$ and $\varepsilon_{i}$ to be the slope vector and error term of the "reduced form"

$$
\begin{aligned}
E\left(Y_{i}-\alpha C H_{i} \mid X_{i}\right) & \equiv X_{i} \gamma \\
Y_{i}-E\left(Y_{i}-\alpha C H_{i} \mid X_{i}\right) & \equiv \varepsilon_{i} .
\end{aligned}
$$

Let the projection of $Z_{i}$ on $W_{i}$ be

$$
\operatorname{Proj}\left(Z_{i} \mid W_{i}\right)=W_{i}^{\prime} \Pi \text {. }
$$

One may easily adapt the analysis in appendix A.2 of AET to obtain a sufficient set of assumptions for Condition 1-IV in that paper or equivalently, (10) above, to hold. The sufficient assumptions are assumptions 1. and 2. above and

$$
\frac{\sum_{\ell=-\infty}^{\infty} E\left(W_{i j} W_{i j-\ell}\right) E\left(\Pi_{j} \Gamma_{j-\ell}\right)}{\sum_{\ell=-\infty}^{\infty} E\left(W_{i j} W_{i j-\ell}\right) E\left(\Gamma_{j} \Gamma_{j-\ell}\right)}=\frac{\sum_{\ell=-\infty}^{\infty} E\left(\tilde{W}_{i j} \tilde{W}_{i j-\ell}\right) E\left(\Pi_{j} \Gamma_{j-\ell}\right)}{\sum_{\ell=-\infty}^{\infty} E\left(\tilde{W}_{i j} \tilde{W}_{i j-\ell}\right) E\left(\Gamma_{j} \Gamma_{j-\ell}\right)},
$$

where $\tilde{W}_{i j}$ is the component of $W_{i j}$ that is orthogonal to $X_{i}$. Roughly speaking $\left({ }^{* * *}\right)$ says that the regression of $Z_{i}$ on $Y_{i}-\alpha C H_{i}$ is equal to the regression of the part of $Z_{i}$ that is orthogonal to $X_{i}$ on the corresponding part of $Y_{i}-\alpha C H_{i}$. One can show that this condition holds given assumptions 1 and 2 under the standard assumption $E\left(\xi_{i} \mid X_{i}\right)=0$. However, $E\left(\xi_{i} \mid X_{i}\right)=0$ is not necessary for (***). For example, the analysis in appendix A.2 AET implies that (***) will also hold if $E\left(\Pi_{j} \Gamma_{j-\ell}\right)$ is proportional to $E\left(\Gamma_{j} \Gamma_{j-\ell}\right)$ regardless of the correlations among the $W_{i j}$. 
equations (3)-(7), one can rewrite

$$
Y_{i}=\alpha \lambda v_{i}+X_{i}^{\prime}[\gamma+\alpha(\beta+\lambda \pi)]+\alpha u_{i}+\varepsilon_{i}
$$

Since $v_{i}$ is orthogonal to $X_{i}$ and $u_{i}$, the asymptotic bias from two stage least squares would be

$$
\begin{aligned}
\operatorname{plim}(\widehat{\alpha}-\alpha) & =\frac{\operatorname{cov}\left(\lambda v_{i}, \varepsilon_{i}\right)}{\operatorname{var}\left(\lambda v_{i}\right)} \\
& =\frac{\operatorname{var}\left(Z_{i}\right)}{\lambda \operatorname{var}\left(v_{i}\right)}\left[E\left(\varepsilon_{i} \mid Z_{i}=1\right)-E\left(\varepsilon_{i} \mid Z_{i}=0\right)\right] \\
& =\frac{\operatorname{var}\left(Z_{i}\right)}{\lambda \operatorname{var}\left(v_{i}\right)} \frac{\operatorname{Var}\left(\varepsilon_{i}\right)}{\operatorname{Var}\left(X_{i}^{\prime} \gamma\right)}\left[E\left(X_{i}^{\prime} \gamma \mid Z_{i}=1\right)-E\left(X_{i}^{\prime} \gamma \mid Z_{i}=0\right)\right]
\end{aligned}
$$

where we have used (11) to obtain (13) from (12). The hypothesis of equal selection on observables and unobservables provides a way of identifying $\left[E\left(\varepsilon_{i} \mid Z_{i}=1\right)-E\left(\varepsilon_{i} \mid Z_{i}=0\right)\right]$, and therefore the asymptotic bias of instrumental variable estimates, since the other terms in the last line of (12) are readily and consistently estimable. AET develops extensions to the case of latent dependent variables, so both probit and linear 2SLS bias calculations are given where appropriate.

We wish to stress at the outset that one should not make too much of the specific estimates of bias, which are based on strong assumptions about the symmetry of selection of observables and unobservables. In AET, we argue that the relationship between the indexes of unobservables that determine $C H_{i}$ and $Y_{i}$ is likely to be weaker than the relationship between the indexes of observables, in part because many of the factors that determine graduation and college attendance are determined after 8th grade and are excluded from $X_{i}$ by design. We are less clear about the force of this argument in the case of $C_{i}$ and the other instruments we consider. The variables $C_{i}, D_{i}$, and $C_{i} \times D_{i}$ could all be correlated with pre and post 8th grade influences on $Y_{i}$ that are not correlated with $C H_{i}$, but these correlations could be stronger or weaker than the link between factors that determine $\mathrm{CH}_{i}$ and $Y_{i}$. However, we suspect that they are considerably weaker, which means that bias estimates will be too large in absolute value.

One may refine the bias calculations to account for the fact that the variation in the instrument may only be over a specific dimension. For example, $D_{i}$ only varies across zip code, and so must be orthogonal to variation in $X_{i}^{\prime} \gamma$ and in $\varepsilon_{i}$ that is within zip code. Consequently, we adjust the bias estimates by using variance in $E\left(X_{i}^{\prime} \gamma\right)$ across zip codes 
relative to the variance within zip codes as a guide to the variance in $E\left(\varepsilon_{i} \mid D_{i}\right)$ relative to the cross area variance in $\varepsilon_{i}{ }^{22}$

Column (1) of Table 5 presents the results, which are quite striking. In the case of high school graduation, for linear 2SLS we calculate a bias of $0.52(0.23)$ in $\widehat{\alpha}$ if we include $D_{i}$ among the set of variables used to form the index of observables and 0.84 (0.26) if we exclude it. These are both huge potential biases, greater in magnitude than the implausibly large 2SLS point estimate, which is repeated in this table for convenience. The table reports a similar calculation in the 2SLS estimate of $\alpha$ when $C O L L_{i}$ is the dependent variable. In this case, the bias estimate under the assumptions leading to (11) is 0.45 (0.21), which is slightly larger than the 2SLS estimate of 0.40. If selection on unobservables follows the same pattern as selection on observables, there is a huge bias in the IV estimates when $C_{i}$ is used as an instrument, at least for the cohort of children sampled in NELS:88. ${ }^{23}$ The results reinforce our conclusions based on the public 8th grade sample. However, we also wish to stress that the bias estimates have large standard errors and are best interpreted as a warning sign of potential trouble rather than a precise estimate of the what the bias is.

The bottom panels of Table 5 repeats the calculations for 12 th grade test scores. These calculations use estimates of the reliability of the NELS:88 tests to provide a rough adjustment for the fact that much of the variance in $\varepsilon_{i}$ is due to noise in the tests and thus is unrelated to $C_{i} \cdot{ }^{24}$ The calculations suggest that there is the potential for substantial bias

\footnotetext{
${ }^{22}$ With sibling data one could refine the calculations to some degree based on the observation that the effects of parents religious background is common to siblings. At least in the context of an additively separable model, the connection between $C_{i}$ and $\varepsilon_{i}$ must involve the component of $\varepsilon_{i}$ that is common to siblings. One could use the value of $\left[E\left(X_{i}^{\prime} \gamma \mid C_{i}=1\right)-E\left(X_{i}^{\prime} \gamma \mid C_{i}=0\right)\right]$ relative to the cross family variance in $X_{i}^{\prime} \gamma$ as a guide to $\left[E\left(\varepsilon_{i} \mid C_{i}=1\right)-E\left(\varepsilon_{i} \mid C_{i}=0\right)\right]$ relative to cross family variation in $\varepsilon_{i}$. Unfortunately, NELS:88 does not identify siblings and, because of its design, is likely to include only siblings who are twins or very close in age.

${ }^{23}$ This conclusion is also supported by calculations not reported that use a two stage probit procedure. See Elder (2002) for details.

${ }^{24}$ The adjustment is performed by multiplying the estimate of $\operatorname{plim}(\hat{\alpha}-\alpha)$ based on (12) by (reliability$\left.R^{2}\right) /\left(1-R^{2}\right)$, where reliability is the estimate of the reliability of the particular test, and $R^{2}$ is the $R^{2}$ of the model for the particular test. To see the justification, let the composite error term be $\varepsilon^{*}=\varepsilon+\varsigma$ where $\varsigma$ is the component of test scores due to noise in the test. One minus the reliability of the test is an estimate of $\operatorname{var}(\varsigma) / \operatorname{var}\left(Y_{i}+\varsigma\right)$ where $Y_{i}$ is the true test score. The value 1 minus the $R^{2}$ of the test score model is an estimate of $[\operatorname{var}(\varepsilon)+\operatorname{var}(\varsigma)] / \operatorname{var}\left(Y_{i}+\varsigma\right)$, and note that $\operatorname{var}(\varepsilon)=[\operatorname{var}(\varepsilon) /(\operatorname{var}(\varepsilon)+\operatorname{var}(\varsigma))] \operatorname{var}\left(\varepsilon^{*}\right)$. Consequently, $\operatorname{var}(\varepsilon)=\frac{\left(1-R^{2}\right)-(1-\text { reliability })}{1-R^{2}} \operatorname{var}\left(\varepsilon^{*}\right)$.

The $R^{2}$ is 0.60 for 12 th grade reading and 0.74 for 12 th grade math (using the 2SLS estimate of the model and ignoring the correlation between $\mathrm{CH}_{i}$ and $\varepsilon_{i}$ ), and the reliability is 0.85 for 12th grade reading and 0.94 for 12 th grade math. Consequently, the correction scales down the bias estimates by 0.625 for reading and 0.770 for math.
} 
when using $C_{i}$ as an instrument, but the estimates are very imprecise. In the case of math the bias estimates of $2.02(0.75)$ and 1.87 (0.74) (depending again on whether $D_{i}$ is used in the calculations) preclude any firm conclusions. In general, we cannot rule out the possibility of a positive effect of Catholic high school attendance on achievement test scores, but the large potential biases are suggestive that the use of $C_{i}$ as an instrument is not a reliable way to assess the magnitude of these effects.

The conclusion that we draw from these calculations is that IV procedures based on $C_{i}$ lead to huge point estimates but may also be subject to a great deal of bias. In this circumstance, $C_{i}$ is not a useful instrumental variable despite its powerful association with $\mathrm{CH}_{i}$. This inference is fully consistent with the evidence for a large direct association between $C_{i}$ and the outcomes in the public 8th grade sample. We do not have a good understanding of why the gap between the IV estimates of the Catholic school effect and the probit or linear probability estimates are so much larger in NELS:88 than in NLS-72 or in High School and Beyond (See Evans and Schwab, 1995). Unfortunately, we lack the rich set of primary school data required to use the relative degree of selection on observables to explore the discrepancy in IV results across data sets. The variability across data sets, which in part may reflect changes over time in the composition of the Catholic population in the U.S., is an additional reason to be cautious about the use of $C_{i}$ as an instrument.

\section{Instrumental Variables Estimates using Proximity to Catholic Schools}

In this section we evaluate proximity $\left(D_{i}\right)$ as a source of identifying variation. The main theoretical justification for $D_{i}$ is that it should affect the costs of attending a Catholic high school, while the main concern is that the location of Catholic high schools may be associated with characteristics of the population, public schools, post-secondary schools, and labor market, all of which influence outcomes.

In Column (2) of Table 1 we report estimates with $D_{i}$ as the excluded instrument. It is important to re-emphasize that because of the nonlinearity of the bivariate probit model, both $D_{i}$ and the interaction between $D_{i}$ and $C_{i}$ play a role in identification in the bivariate probit case (as well as the method of using two-stage probits), so the 2SLS estimates are cleaner in this regard. The 2SLS estimate of -0.04 (0.10) is surprising but too imprecise for 
us to draw any inferences from it. The 2SLS estimate for $C O L L_{i}$ is $0.31(0.11)$ in NELS:88 and $0.44(0.20)$ in NLS-72. Both estimates are much larger than the estimated marginal effect of 0.085 from the univariate probit in NELS:88 and 0.070 from NLS-72. Column (2) of Table 2 presents the results for test scores in NELS:88 and NLS-72. These coefficients vary across specifications, but for the NLS-72 test scores they imply very large effects. On their face, these findings appear implausible, so we next explore the degree to which they are influenced by bias using the same methods as in section 3 .

In Column (3) of Table 3a we report the relationship between a wide set of observables in NELS:88 and a student's distance from the nearest Catholic high school. For simplicity we collapsed the vector $D_{i}$ into a dummy variable $D 6_{i}$, which is equal to 1 for person $i$ if she lives less than 6 miles from the nearest Catholic high school and zero otherwise, and present the difference in these means by $D 6_{i}$. Among the eighth grade measures, such as teacher evaluations of the student's behavior, there is little difference between those who live close to Catholic high schools and those who do not. However, there is a positive relationship between $D_{i}$ and most of the family background measures. There is also a positive association between proximity and both student and parental educational expectations. Similar differences by $D 6_{i}$ appear in NLS-72 (Table 3b). These differences in family motivation and students' home environment introduce the possibility that there might also be unmeasured differences which could affect outcomes and lead to bias in models using $D_{i}$ as an instrumental variable in both NLS-72 and NELS:88.

In column (2) of Table 4 we report estimates of the bias coefficient $\psi$ based on the equation

$$
Y_{i}=X_{i}^{\prime} \gamma+\left[D_{i}^{\prime} \widehat{\lambda}\right] \psi+\omega_{i}
$$

for public eighth graders from NELS:88. In (14), $D_{i}^{\prime} \hat{\lambda}$ is the index of distance dummies weighted by their coefficients $\widehat{\lambda}$ in the first stage equation for $C H_{i}$. The estimate of $\psi$ is -0.05 (0.12) in the equation for $H S_{i}$ and $0.37(0.12)$ in the equation for $C O L L_{i}$. There is not much evidence for bias in the $H S_{i}$ equation given the large standard error, but this is not surprising given that the 2SLS estimate is also noisy and does not indicate a positive effect. For $C O L L_{i}$, the implied bias is slightly larger than the 2SLS estimate, reaffirming the notion that one should not put too much stock in inferences using $D_{i}$ as an instrument for college attendance, at least in NELS:88. In the case of reading the bias check is uninformative given the large standard error on $\psi$. For 12 th grade math scores, the evidence in favor of a 
positive effect of $\mathrm{CH}_{i}$ is dampened by the fact that implied bias estimates are large in this case as well. Given both the evidence of endogeneity and the large standard errors of the 2SLS estimates, we conclude that the 2SLS estimates using $D_{i}$ are not useful in drawing conclusions regarding test scores. ${ }^{25}$

Finally, we apply the AET methodology for assessing the potential bias due to selection on unobservables. The extension of the methods to account for fact that $D_{i}$ is a vector is straightforward, with the relevant condition analogous to (10) being $\frac{\operatorname{cov}\left(D_{i}^{\prime} \lambda, \varepsilon_{i}\right)}{\operatorname{var}\left(\varepsilon_{i}\right)}=$ $\frac{\operatorname{cov}\left(D_{i}^{\prime} \lambda, X_{i}^{\prime} \gamma\right)}{\operatorname{var}\left(X_{i}^{\prime} \gamma\right)}{ }^{26}$ The results are in Column (2) of Table 5. The estimates computed under the assumption of equal selection on observables and unobservables show the potential for large positive biases for both $H S_{i}$ and $C O L L_{i}$. The fact that the bias estimates for the two different outcomes have the same sign is not surprising, since it reflects the similarity in the effects of $X_{i}$ on the two education outcomes. While the specific bias estimates are noisy and are probably overstated for reasons discussed above, the large estimate for $C O L L_{i}$ suggests that the 2SLS coefficients are not informative. Finally, for 12 th grade math scores, the estimates of 1.72-1.76 (depending on whether $C_{i}$ is included in the calculations involving $X_{i}^{\prime} \gamma$ ) again do not preclude a small Catholic schooling effect, but instrumental variables estimates using $D_{i}$ do not provide a reliable gauge of the strength or even the sign of the effect.

Although we are unable to directly evaluate $D_{i}$ as an instrument in NLS-72 other than the informal analysis based on Table 3b, the calculations based on NELS:88 cast further doubts on the validity of the large estimates obtained for outcomes in this data set.

\section{Instrumental Variables Estimates using the Interac- tion}

Finally, we turn to the interaction between $C_{i}$ and $D_{i}$ as the source of identifying variation. In Column (3) of Table 1 we report probit, bivariate probit, linear probability and 2SLS estimates of the effect of $\mathrm{CH}_{i}$ on high school graduation and college attendance. Column (3) of Table 2 presents results for test scores. All of the models include both $C_{i}$ and $D_{i}$ among the controls.

\footnotetext{
${ }^{25}$ It should be noted that the public 8 th grade analysis is likely less informative for $D_{i}$ than for $C_{i}$ because of the likelihood that distance from Catholic elementary school and distance from Catholic high school are closely related. Consequently, selection issues may have a bigger effect on the coefficient on the index when the distance variables are involved than when only religion is involved.

${ }^{26}$ Note that equation (10) can be written similarly as $\frac{\operatorname{Cov}\left(\varepsilon_{i}, Z_{i}\right)}{\operatorname{var}\left(\varepsilon_{i}\right)}=\frac{\operatorname{Cov}\left(X_{i}^{\prime} \gamma, Z_{i}\right)}{\operatorname{var}\left(X_{i}^{\prime} \gamma\right)}$ because $\varepsilon_{i}$ and $v_{i}$ are orthogonal $X_{i}$.
} 
The results vary across the different outcomes. In the case of educational attainment, the bivariate probit and 2SLS point estimates are negative in two of the three cases. For test scores, the 2SLS estimates lie below the OLS ones in three of the four cases, with 12th grade math score coefficients being fairly large and negative in both data sets. However, in all cases in NELS the standard errors are too large in relation to the difference between the OLS and 2SLS estimates for the 2SLS estimates to help much in modifying conclusions about $\alpha$. This is less true in the NLS-72.

We have investigated the properties of the instrument using the same set of procedures that we used for $C_{i}$ and $D_{i}$ with the same bottom line. Given the imprecision in some of the estimates, the lack of previous work using $C_{i} \times D_{i}$ as an instrument, and space considerations, we will not get into the details. ${ }^{27}$ However, the weight of the evidence in Tables 1-5 leads us to be very skeptical of the interaction as an exclusion restriction. In particular, there is evidence in both data sets that the difference between Catholics and non-Catholics in favorable family background characteristics rises with distance from the nearest Catholic high school. If the link between $C_{i} \times D_{i}$ and $\varepsilon_{i}$ followed the same pattern, the 2SLS estimates would be biased downward. We suspect that this underlies that the negative coefficients for some outcomes in both data sets, particularly NLS72. We conclude that $C_{i} \times D_{i}$ is not a very useful source of variation for the purpose of estimating the Catholic school effect, at least not in the context of NELS:88 or NLS-72.

\footnotetext{
${ }^{27}$ In Column (4) of Table 3a we report the coefficient on $C \times D 6_{i}$ from regressions of the various background and outcome variables indicated in the rows on $C_{i}, D_{i}$, and $C_{i} \times D 6_{i}$. The results for the eighth grade measures are mixed, with $C_{i} \times D 6_{i}$ being positively associated with indicators for whether the student got into a fight at school, but negatively correlated with the "repeated grade" indicator. There are also slight comparative advantages in eighth grade GPA and reading scores. In contrast, family background, student expectations, and parental expectations are generally negatively correlated with $C_{i} \times D 6_{i}$, with striking differences in parental education levels and expectations.

For NLS-72, the estimates in Table 3b imply that the difference in mother's and father's education between Catholics and non- Catholic students who live within 6 miles of a Catholic high school is 0.33 and 0.32 years lower, respectively, than the difference among Catholic and non Catholic student who live more than 6 miles from a Catholic high school. The incomes of Catholics relative to non-Catholics also rise with distance, and all of these figures are nearly identical to the corresponding ones in NELS:88. Additionally, student educational expectations are strongly correlated with $C_{i} \times D 6_{i}$, with a coefficient of -0.06 (0.016). We have not investigated why low SES Catholics are disproportionately located near Catholic high schools, but if the unobservable parental traits that influence the outcomes we study follow a similar pattern, then our 2SLS estimates of the effect of Catholic schools are likely to be negatively biased for both the NLS-72 and NELS:88 cohorts.
} 


\section{Conclusion}

We present evidence on the validity of using three sources of variation Catholic school attendance - religious affiliation, proximity to Catholic schools, and the interaction between religion and proximity - as a way to identify the effect of attending Catholic high school. The simplest evidence comes from the relationship between the instrument candidates and the means of a large set of observable measures in NELS:88 and NLS-72. In NELS:88, we use the fact that very few students who attend public eighth grade go on to attend Catholic high school as the basis for interpreting the association between an outcome and an instrument in a sample of public eighth graders as an estimate of the direct link between the instrument and the outcome in question. The final approach applies a method introduced in AET that takes advantage of the rich set of observable demographic, family background, and eighth grade outcome data in NELS:88. The idea is that if the observed variables included as controls are representative of the factors that determine the outcomes, then the relationship between observables and the instruments can be used as a guide to the relationship between the error term in the outcome equation and the instruments.

We will not attempt to restate all the results, which are sometimes contradictory across outcomes and data sets. Our main conclusion is that none of the candidate instruments is a useful source of identification of the Catholic school effect, at least in the NELS:88 data set. For example, we find a strong relationship between Catholic religion and educational achievement in the sample of public eighth graders, who almost never attend Catholic high school. We obtain similar results for distance from the nearest Catholic high school in the case of college attendance. We also find a fairly strong relationship between the instruments and in the index of observed variables that determine the outcomes. Although we cannot formally evaluate the magnitude of bias in NLS-72, the strong relationship between observables and distance in these data, in conjunction with the NELS:88 findings, raises the likelihood of serious doubts that the results found are due to a genuine causal effect.

We wish to stress that we are not advocating literal interpretation of specific estimates of bias based on the public eighth grade sample or the AET methodology. However, the evidence strongly suggests that the candidate instruments are not valid instrumental variables for Catholic high school. Future research on the effects of Catholic schooling will hopefully introduce new methods, such as those described in AET, which do not necessitate exclusion

restrictions. Alternatively, future work may involve either new exclusion restrictions alto- 
gether or different measures of religion or proximity to Catholic schools than the ones that we and others have considered. Finally, experiments along the lines of Howell and Peterson (2002), while difficult to run, have large advantages in identifying the effect of Catholic school attendance on outcomes.

\section{References}

[1] Alexander, Karl L., and Aaron M. Pallas, "School Sector and Cognitive Performance: When is a Little a Little," Sociology of Education, LVIII (1985), 115-128.

[2] Altonji, Joseph G., and Rosa Matzkin, "Panel Data Estimators for Nonseparable Models with Endogenous Regressors" NBER Working Paper No. T0267 March 2001.

[3] Altonji, Joseph G., Todd E. Elder, and Christopher R. Taber, "Selection on Observed and Unobserved Variables: Assessing the Effectiveness of Catholic Schools," Northwestern University, revised April 2002.

[4] Angrist, Joshua D., "Instrumental Variables Estimation of Average Treatment Effects in Econometrics and Epidemiology," National Bureau of Economic Research, Technical Working Paper No. 115, November 1991.

[5] Angrist and Evans, "Children and their Parent's Labor Supply: Evidence from Exogenous Variation in Family Size" American Economic Review, 88 (1988), 450-477.

[6] Bronars, Stephen G. , and Jeff Grogger, "The Economic Consequences of Unwed Motherhood: Using Twins as a Natural Experiment," American Economic Review 80(1994), $1141-56$.

[7] Bryk, Anthony S., Valerie E. Lee, and Peter B. Holland, Catholic Schools and the Common Good, Cambridge, Mass. : Harvard University Press, 1993.

[8] Cameron, Stephen V. and Heckman, James J., "Life Cycle Schooling and Dynamic Selection Bias: Models and Evidence for Five Cohorts of American Males," Journal of Political Economy, 106(1998).

[9] Card, David and Alan B. Krueger, "The Economic Returns to School Quality: A Partial Survey," Working Paper \#334, Industrial Relations Section, Princeton University, 1994. 
[10] Chubb, John E., and Terry M. Moe, Politics, Markets, and America's Schools (Washington, D.C.: The Brookings Institution, 1990).

[11] Coleman, James S., Thomas Hoffer, and Sally Kilgore, High School Achievement: Public, Catholic, and Private Schools Compared (New York, NY: Basic Books, Inc., 1982).

[12] Coleman, James S., and Thomas Hoffer, Public and Private Schools: The Impact of Communities (New York, NY: Basic Books, Inc., 1987).

[13] Cookson, Peter W., Jr., "Assessing Private School Effects: Implications for School Choice," in Edith Rasell and Richard Rothstein, eds., School Choice: Examining the Evidence (Washington, D.C.: Economic Policy Institute, 1993).

[14] Currie, Janet, and Thomas Duncan, "Does Head Start Make a Difference?" American Economic Review, 85 (1990), 341-64.

[15] Engen, Eric, William Gale, and John Karl Sholz, "The Illusory Effects of Saving Incentives on Saving," Journal of Economic Perspectives, 10 (1996), 113-138.

[16] Evans, William N., and Robert M. Schwab, "Finishing High School and Starting College: Do Catholic Schools Make a Difference?" Quarterly Journal of Economics, 110 (1995), 947-974.

[17] Evans, William N., and Robert M. Schwab, "Who Benefits from Private Education: Evidence from Quantile Regressions," Department of Economics Working Paper, University of Maryland, August 1993.

[18] Figlio, David N., and Joe A. Stone, "Are Private Schools Really Better?," Research in Labor Economics, (2000).

[19] Goldberger, Arthur S., and Glen C. Cain, "The Causal Analysis of Cognitive Outcomes in the Coleman, Hoffer and Kilgore Report," Sociology of Education, LV (1982), 103-122.

[20] Grogger, Jeff and Derek A. Neal, "Further Evidence on the Effects of Catholic Secondary Schooling," Brookings-Wharton Papers on Urban Affairs, 2000, 151-201.

[21] Heckman, James J., "Varieties of Selection Bias," American Economic Review, 80(1990). 
[22] Hoxby, Caroline Minter., "Do Private Schools Provide Competition for Public Schools," NBER Working paper, 1995.

[23] Howell, William G. and Paul E. Peterson, The Education Gap:Vouchers and Urban Schools, Brookings Press, (2002).

[24] Jepsen, Christopher, "The Effectiveness of Catholic Primary Schools, " forthcoming in Journal of Human Resources.

[25] Jacobsen, Joyce P., James W. Pearce III, and Joshua L. Rosenbloom, "The Effect of Childbearing on Married Women's Labor Supply and Earnings," Journal of Human Resources 34(3), Summer 1999, pp. 449-474.

[26] Ludwig, Jens, "Educational Achievement in Public, Private, and Catholic Schools: New Evidence on What We Know (and Don't Know)," working paper, Georgetown University, 1997.

[27] Murnane, Richard J., "A Review Essay - Comparisons of Public and Private Schools: Lessons from the Uproar." Journal of Human Resources 19 (1984), 263-77.

[28] Neal, Derek, "The Effects of Catholic Secondary Schooling on Educational Attainment," Journal of Labor Economics 15 (1997), 98-123.

[29] Sander, William H. Catholic Schools: Private and Social Effects. Boston: Kluwer Academic Publishers, 2001.

[30] Tyler, Brian S., "An Analysis of Public and Catholic Secondary Education and the Earnings of Men," University of Chicago Ph.D. Thesis (1994).

[31] Taber, Christopher, "Semiparametric Identification and Heterogeneity in Discrete Choice Dynamic Programming Models," Journal of Econometrics 96(2000), 201-229.

[32] Udry, Christopher, "Gender, Agricultural Production, and the Theory of the Household", Journal of Political Economy, 104 (1996), 1010-1046.

[33] Witte, John F., "Private School Versus Public School Achievement: Are There Findings That Should Affect the Educational Choice Debate," Economics of Education Review, XI (1992), 371-394. 


\section{Appendix: A Comparison Between Bivariate Probits and Two Stage Least Squares}

Evans and Schwab (1995) and Neal (1997) apply bivariate probits of Catholic schooling and an educational outcome such as either high school graduation or college attendance using data from High School and Beyond and NLSY, respectively. Both papers emphasize the importance of an exclusion restriction in the model for identification. As we have already noted, Evans and Schwab (1995) primarily use Catholic religion, excluding it from the outcome equation but including it in the Catholic schooling decision. Neal (1997) uses an indicator for Catholic religion along with county level measures of the density of Catholics and the availability of Catholic schools. Both of these papers find positive effects of Catholic schools that are estimated fairly precisely. The bivariate probit results reported in this paper generally follow the same pattern, with estimates being much more precise and reasonable than linear specifications. It is therefore worth investigating the reasons why our instrumental variables results are so noisy and in many cases seem unreasonable, while the bivariate probits seem to show plausible results that are precisely estimated.

At this point it is useful to more closely examine identification in the bivariate probit model. The specification used in Neal (1997), Evans and Schwab (1995), and here is

$$
\begin{aligned}
C H_{i} & =1\left(g\left(X_{i}\right)+u_{i}>0\right) \\
Y_{i} & =1\left(\alpha C H_{i}+f\left(Z_{i}\right)+\varepsilon_{i}>0\right),
\end{aligned}
$$

where $1(\cdot)$ is the indicator function taking the value one if its argument is true and zero otherwise. Identification of the $\alpha$ coefficient is the primary focus of these studies. This model is similar to other types of selection models (see, e.g., Heckman, 1990, Cameron and Heckman, 1998, or Taber, 2000), so we appeal to the results in that literature.

As is well known, identification of $\alpha$ essentially requires two assumptions:

1. Either (a) parametric assumptions on the distribution of the error terms or (b) support conditions on $g\left(X_{i}\right)$.

2. Either (a) an exclusion restriction specifying that a variable belongs in the Catholic schooling equation but not in the selection equation or (b) parametric restrictions on $f$ and $g$. 
That is, identification can be achieved by combining either 1 (a) or 1(b) with either 2(a) or 2(b). Evans and Schwab (1995) and Neal (1997) implicitly assume that identification comes from the exclusion restrictions. However, both papers (and this one) also assume $g$ and $f$ are linear, i.e., $g\left(X_{i}\right)=X_{i}^{\prime} \beta$ and $f\left(Z_{i}\right)=Z_{i}^{\prime} \gamma$, which can be shown to satisfy $2(\mathrm{~b})$ so that an exclusion restriction is not necessary. Since identification can be achieved from either the exclusion restriction or the linearity assumption, in practice it is difficult to know which assumption drives identification in the empirical application.

Evans and Schwab (1995) experiment with both bivariate probits and two stage least squares. They also employ two different instruments, Catholic religion and the percentage of Catholics in the county, which are similar to Neal's (1997) exclusion restrictions. When they run two stage least squares, they find implausible estimates in some specifications, depending on the specific exclusions maintained. Neal (1997) does not report results based on linear 2SLS.

In order to better assess what is identifying the bivariate probit models, as well as facilitate an easier comparison between the results of this paper and the previous literature, we examine the sensitivity of our results from NLS-72 to different specifications using bivariate probits. We use a sample design based loosely on Neal (1997), in that we look at individuals from urban areas and examine separate effects for blacks and whites. ${ }^{28}$ The results are reported in Table A1. We obtain results which are similar to Neal's in several respects. First, the univariate probit coefficient of 0.640 (0.198) implies a large positive effect for non-whites. Second, the coefficient from a bivariate probit specification which uses Neal's exclusion restrictions for urban minorities, Catholic religion and the county-level ratio of Catholics to the overall population, is actually larger than the univariate one- 0.879 (0.523)-although this difference is not significantly different from zero. Third, the estimates appear at first glance to be of a reasonable magnitude. In particular, the probit coefficients are comparable to the ones reported both in Neal (1997) and in Table 1 of this paper. However, the marginal effects of 0.239 and 0.329 for the univariate and bivariate models, respectively, are suspiciously large.

Table A1 also shows that for urban minorities, the estimated bivariate probit coefficients are relatively insensitive to exclusion restrictions, and appear to be largely driven by the functional form assumptions embedded in these models. To see this, note that the precision

\footnotetext{
${ }^{28}$ We have not replicated the analysis for NELS:88 for several reasons. Most importantly, we could not accurately match students to counties, as no county-level identifiers are available in these data at present.
} 
of the estimates does not vary much with specification, even when only a "weak" instrument such as $C_{i} \times D_{i}$ is excluded - or there are no excluded instruments at all (bottom row). The standard error of the coefficient on $\mathrm{CH}_{i}$ is smaller in both of these cases than when the more powerful instrument $C_{i}$ is excluded, which seems at odds with the notion that the exclusions are driving identification. In contrast, 2SLS estimates swing wildly across specifications, with the results being similar to Evans and Schwab (1995) and our own earlier results; we typically find improbably large effects with standard errors that are sufficiently large that any estimate within the realm of plausibility would not be significantly different from zero at conventional levels. In the most precisely-estimated specification involving all three exclusion restrictions, the coefficient of 0.331 (0.254) implies a huge effect yet is not significant. In the case of the weakest instrument, $C_{i} \times D_{i}$, the coefficient of $2.572(2.442)$ is so large that it cannot be interpreted literally within the linear probability framework, yet it is still insignificantly different from zero.

The results for whites are again fairly similar across specifications, although the precision of the estimates now varies with the choice of instrument. In the 2SLS case, both precision and the coefficients themselves are relatively constant except when $C_{i} \times D_{i}$ is used as an exclusion restriction. It appears that in this subsample, the exclusion restrictions are driving a larger share of identification than they were for urban minorities, but that the linear index assumption in conjunction with normality is still playing a large role.

Although the specifications of Table A1 do not involve exact replications of the analyses of either Evans and Schwab (1995) or Neal (1997), ${ }^{29}$ we believe that they do shed some light on the sources of the apparent discrepancies in the results. Table A1 suggests that the proximity measures in both of these studies do not play a key role in identification in NLS-72, as standard errors in the 2SLS models are prohibitively large in cases in which Catholic religion is not an excluded instrument. Bivariate probit models can sometimes produce misleading results which are consistent with a reasonably exogenous instrumental variable, when in fact identification is stemming from an invalid instrument in combination with functional form assumptions. In order to isolate the role of each of these factors, it is necessary to implement IV strategies that rely on nothing other than exclusion restrictions

\footnotetext{
${ }^{29}$ We could not replicate Neal (1997) exactly because he used an indicator for whether students attended a Catholic high school in the National Longitudinal Survey of Youth that is not available in the public release version of the data set. We experimented with NLSY using an indicator for whether the student attended public school. We obtained results qualitatively similar to those based on NLS-72, with the bivariate probit results being even less sensitive to exclusion restrictions than in NLS-72.
} 
for identification. 
Table 1

Probit, Bivariate Probit, OLS, and 2SLS Estimates of Catholic Schooling Effects

NELS:88 and NLS-72

Weighted, Marginal Effects of Nonlinear Models Reported, (Huber-White Standard Errors in Parentheses)

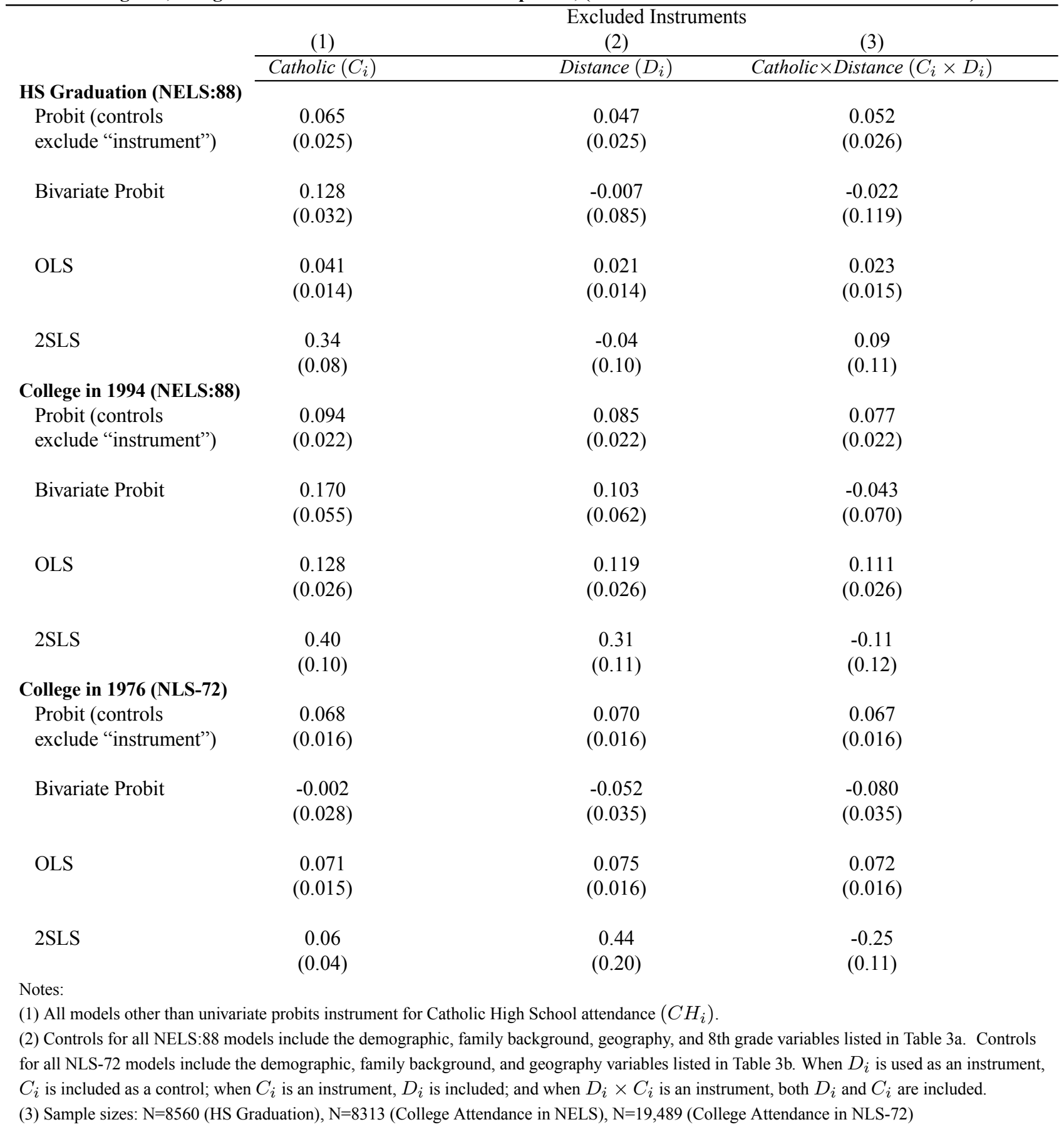


Table 2

OLS and 2SLS estimates of Catholic Schooling Effects

NELS:88 and NLS-72

Weighted, (Huber-White Standard Errors in Parentheses)

\begin{tabular}{lccc}
\hline & \multicolumn{3}{c}{ Excluded Instruments } \\
& $(1)$ & $(2)$ & $(3)$ \\
\cline { 2 - 4 } & Catholic $\left(C_{i}\right)$ & Distance $\left(D_{i}\right)$ & Catholic $\times$ Distance $\left(C_{i} \times D_{i}\right)$ \\
12th Grade Reading Score (NELS:88) & & & \\
$\quad$ OLS & $1.16(0.37)$ & $1.03(0.37)$ & $1.14(0.38)$ \\
2SLS & $1.40(1.54)$ & $-1.09(1.84)$ & $1.24(1.82)$ \\
12th Grade Math Score (NELS:88) & & & \\
OLS & $1.03(0.31)$ & $1.00(0.31)$ & $0.92(0.32)$ \\
2SLS & $2.64(1.21)$ & $2.43(1.45)$ & $-2.63(1.57)$ \\
& & & \\
12th Grade Reading Score (NLS-72) & & & \\
OLS & $2.06(0.34)$ & $2.54(0.37)$ & $0.50(0.36)$ \\
2SLS & $-1.34(0.99)$ & $8.69(4.53)$ & \\
& & & $1.71(0.36)$ \\
12th Grade Math Score (NLS-72) & $1.52(0.33)$ & $1.77(0.35)$ & $-3.94(2.27)$ \\
$\quad$ OLS & $-0.07(0.96)$ & $11.05(4.47)$ & \\
2SLS & & & \\
\hline
\end{tabular}

Notes:

(1) All 2SLS models instrument for Catholic High School attendance $\left(\mathrm{CH}_{i}\right)$.

(2) Controls for all models include those described in notes to Table 1. When $D_{i}$ is used as an instrument,

$C_{i}$ is included as a control; when $C_{i}$ is an instrument, $D_{i}$ is included; and when $D_{i} \times C_{i}$ is an instrument,

both $D_{i}$ and $C_{i}$ are included as controls.

(3) Sample sizes: $N=8,166$ (NELS 12th Reading), $N=8,119$ (NELS 12th Math)

$\mathrm{N}=16,276$ (NLS Academic Years of School), N=14,671 (NLS Reading and Math scores), 
Table 3a

Comparison of Means of Key Variables

by Value of Distance, Catholic, and their Interaction

NELS:88

\begin{tabular}{|c|c|c|c|c|}
\hline & (1) & (2) & (3) & (4) \\
\hline & Overall Mean & Difference by $C_{i}$ & Difference by $D_{i}$ & Difference by $C_{i} \times D_{i}$ \\
\hline \multicolumn{5}{|l|}{ Demographics } \\
\hline Female & 0.50 & 0.01 & 0.00 & 0.00 \\
\hline Asian & 0.04 & 0.01 & 0.04 & -0.02 \\
\hline Hispanic & 0.10 & 0.19 & 0.08 & 0.03 \\
\hline Black & 0.13 & -0.15 & 0.08 & -0.13 \\
\hline White & 0.73 & -0.05 & -0.20 & 0.12 \\
\hline \multicolumn{5}{|l|}{ Family Background } \\
\hline Mother's education & 13.14 & -0.26 & 0.17 & -0.36 \\
\hline Father's education & 13.42 & -0.07 & 0.17 & -0.31 \\
\hline Log of family income & 10.20 & 0.11 & 0.12 & -0.02 \\
\hline Mother only in house & 0.15 & -0.04 & 0.02 & -0.03 \\
\hline Parent married & 0.78 & 0.06 & -0.02 & 0.03 \\
\hline \multicolumn{5}{|l|}{ Geography } \\
\hline Rural & 0.32 & -0.15 & -0.44 & 0.05 \\
\hline Suburban & 0.44 & 0.06 & 0.08 & 0.00 \\
\hline Urban & 0.24 & 0.09 & 0.36 & -0.05 \\
\hline \multicolumn{5}{|l|}{ Expectations } \\
\hline Schooling expectation & 15.17 & 0.15 & 0.31 & -0.06 \\
\hline Very sure to graduate high school & 0.83 & -0.01 & 0.00 & -0.01 \\
\hline Parents expect some college & 0.88 & 0.04 & 0.05 & -0.02 \\
\hline Parents expect college grad & 0.78 & 0.03 & 0.06 & -0.04 \\
\hline Expect white collar job & 0.46 & 0.03 & 0.06 & -0.01 \\
\hline \multicolumn{5}{|l|}{ 8th Grade Variables } \\
\hline Delinquency Index & 0.69 & -0.05 & 0.03 & -0.04 \\
\hline Got into fight & 0.27 & -0.01 & 0.01 & 0.05 \\
\hline Rarely completes homework & 0.21 & -0.05 & 0.00 & 0.00 \\
\hline Frequently disruptive & 0.13 & -0.02 & -0.01 & 0.00 \\
\hline Repeated grade $4-8$ & 0.08 & -0.03 & 0.01 & -0.03 \\
\hline Risk Index & 0.72 & -0.07 & -0.01 & 0.01 \\
\hline Grades Composite & 2.89 & 0.04 & 0.00 & 0.07 \\
\hline Unpreparedness Index & 10.82 & 0.00 & 0.08 & -0.09 \\
\hline 8th Grade reading score & 50.32 & 0.40 & 0.03 & 1.15 \\
\hline 8th Grade math score & 50.33 & 0.55 & 0.45 & 0.06 \\
\hline \multicolumn{5}{|l|}{ Outcomes } \\
\hline 10th Grade reading score & 50.16 & 0.65 & 0.58 & 0.60 \\
\hline 10th Grade math score & 50.21 & 0.93 & 0.75 & -0.50 \\
\hline 12th Grade reading score & 50.40 & 0.52 & 0.88 & -0.17 \\
\hline 12th Grade math score & 50.38 & 1.18 & 1.03 & -0.70 \\
\hline Enrolled in 4 year college in 1994 & 0.29 & 0.08 & 0.08 & -0.05 \\
\hline HS Graduate & 0.84 & 0.07 & 0.01 & 0.01 \\
\hline Attended Catholic HS & 0.06 & 0.13 & 0.12 & 0.15 \\
\hline
\end{tabular}

Notes:

(1) Difference by $C_{i} \times D_{i}$ is obtained from the coefficient on $C_{i} \times D_{i}$ in a regression including $C_{i}$ and $D_{i}$ as controls

(2)Sample Size: $N=16,070$ 
Table 3b

Comparison of Means of Key Variables

by Value of Distance, Catholic, and their Interaction

NLS-72

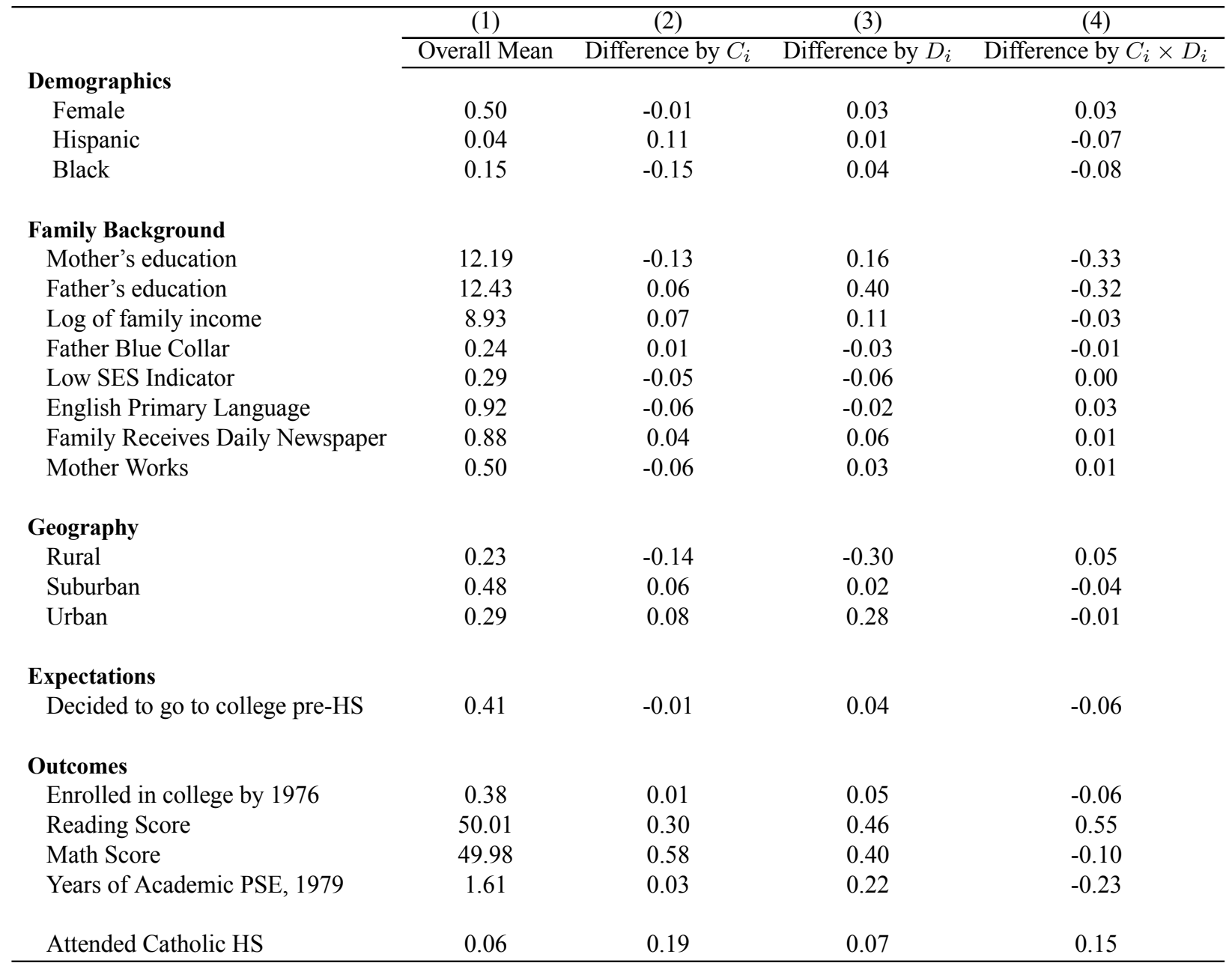

Notes:

(1) Difference by $C_{i} \times D_{i}$ is obtained from the coefficient on $C_{i} \times D_{i}$ in a regression including $C_{i}$ and $D_{i}$ as controls (2)Sample Size: N=19,921 
Table 4

Comparison of 2SLS Estimates ${ }^{1}$ and Bias Implied by OLS Estimation of $Y_{i}=X_{i}^{\prime} \gamma+\left[Z_{i}^{\prime} \widehat{\lambda}\right] \psi+\omega_{i}$ on the Public Eighth Grade Subsample ${ }^{2}$; Various Outcomes and instruments; NELS:88 Sample Weighted, (Huber-White Standard Errors in Parentheses)

\begin{tabular}{|c|c|c|c|}
\hline \multirow[t]{3}{*}{ OUTCOME $(Y)$} & \multicolumn{3}{|c|}{ INSTRUMENTS $\left(Z_{i}\right)$} \\
\hline & (1) & (2) & (3) \\
\hline & Catholic & Distance & Catholic $\times$ Distance \\
\hline \multicolumn{4}{|l|}{ High School Graduation } \\
\hline Implied Bias in 2SLS $(\psi)$ & $0.34(0.08)$ & $-0.05(0.12)$ & $0.15(0.12)$ \\
\hline 2SLS Coefficient & $0.34(0.08)$ & $-0.04(0.10)$ & $0.09(0.11)$ \\
\hline \multicolumn{4}{|l|}{ College Attendance } \\
\hline Implied Bias in 2SLS $(\psi)$ & $0.29(0.11)$ & $0.37(0.12)$ & $-0.23(0.13)$ \\
\hline 2SLS Coefficient & $0.40(0.10)$ & $0.31(0.11)$ & $-0.11(0.12)$ \\
\hline \multicolumn{4}{|l|}{ 12th Grade Reading Score } \\
\hline Implied Bias in 2SLS $(\psi)$ & $0.54(1.68)$ & $-0.51(2.08)$ & $-0.50(1.99)$ \\
\hline 2SLS Coefficient & $1.40(1.54)$ & $-1.09(1.84)$ & $1.24(1.82)$ \\
\hline \multicolumn{4}{|l|}{ 12th Grade Math Score } \\
\hline Implied Bias in 2SLS $(\psi)$ & $1.85(1.41)$ & $1.83(1.69)$ & $-4.37(2.06)$ \\
\hline 2SLS Coefficient & $2.64(1.21)$ & $2.43(1.45)$ & $-2.63(1.57)$ \\
\hline
\end{tabular}

Notes:

(1) Controls for all models include those described in notes to Table 1. In Column 1, D is included as a control; in Column 2, $C_{i}$ is included as a control; and in Column 3, both $D_{i}$ and $C_{i}$ are included as controls.

(2) The model $Y_{i}=X_{i}^{\prime} \gamma+\left[Z_{i}^{\prime} \widehat{\lambda}\right] \psi+\omega_{i}$ is estimated by OLS using the NELS:88 sample of those who attended public eighth grade schools. Sample sizes: N=7,701 (HS Graduation), N=7,481 (College Attendance), N=7377 (12th reading), $\mathrm{N}=7380$ (12th math). $\widehat{\lambda}$ is the coefficient on $Z_{i}$ in the first stage equation for $C H_{i}$. The sample sizes for the first stage equations are listed in Tables 1 and 2 for the various outcomes. The 2SLS coefficients are from Tables 1 and 2.

(3) Reported standard errors of $\psi$ account for the fact that $\widehat{\lambda}$ is previously estimated from a model of $C H_{i}$ attendance. 
Table 5

Estimates of Catholic Schooling Effects and Estimates of Potential Bias

Using AET Methodology, NELS:88

Weighted, (Huber-White Standard Errors in Parentheses)

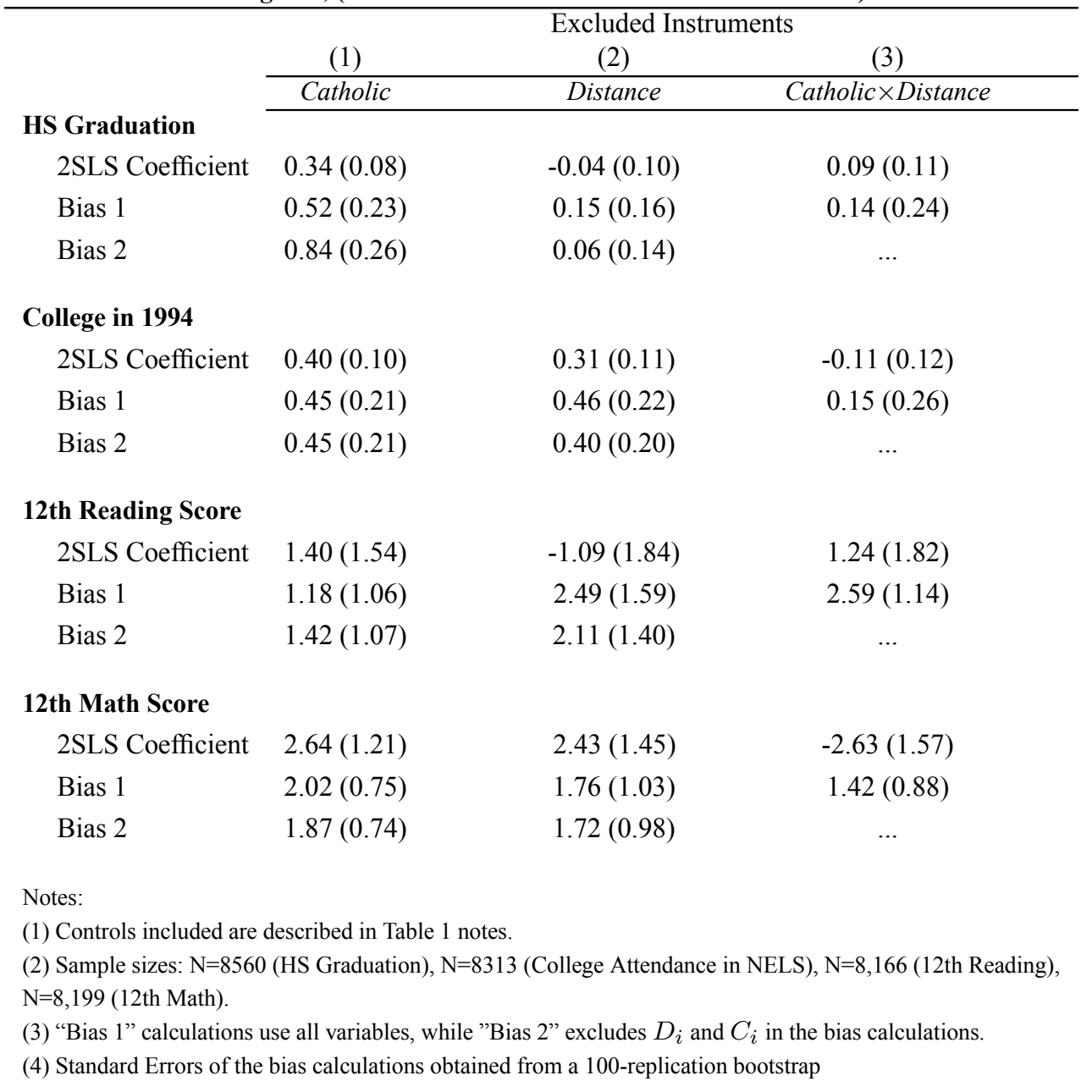


Table A1

Comparison of Linear and Non-Linear Models of College Attendance in NLS-72

(Standard Errors in Parentheses)

[Marginal Effects of Non-Linear Models in Brackets]

\begin{tabular}{|c|c|c|c|c|}
\hline & \multicolumn{4}{|c|}{ Sample } \\
\hline & \multicolumn{2}{|c|}{ Non-whites in cities $(\mathrm{N}=1532)$} & \multicolumn{2}{|c|}{ Whites in cities $(\mathrm{N}=5326)$} \\
\hline & $\begin{array}{l}\text { Nonlinear } \\
\text { Models } \\
\text { (Probits) }\end{array}$ & $\begin{array}{c}\text { Linear } \\
\text { Models } \\
(\text { OLS/2SLS })\end{array}$ & $\begin{array}{l}\text { Nonlinear } \\
\text { Models } \\
\text { (Probits) }\end{array}$ & $\begin{array}{c}\text { Linear } \\
\text { Models } \\
\text { (OLS/2SLS) }\end{array}$ \\
\hline $\begin{array}{l}\text { Single Equation Model } \\
\text { (OLS/Probit) }\end{array}$ & $\begin{array}{c}0.640 \\
(0.198) \\
{[0.239]}\end{array}$ & $\begin{array}{c}0.239 \\
(0.070)\end{array}$ & $\begin{array}{c}0.253 \\
(0.062) \\
{[0.093]}\end{array}$ & $\begin{array}{c}0.093 \\
(0.022)\end{array}$ \\
\hline $\begin{array}{l}\text { Two Equation Models: } \\
\text { Excluded Instruments: } \\
{ }_{0} C C H_{i} \text { and } C H / P_{i}\end{array}$ & $\begin{array}{c}1.471 \\
(0.442) \\
{[0.517]}\end{array}$ & $\begin{array}{c}1.375 \\
(0.583)\end{array}$ & $\begin{array}{c}0.048 \\
(0.250) \\
{[0.018]}\end{array}$ & $\begin{array}{c}0.115 \\
(0.158)\end{array}$ \\
\hline$C_{i}$ and $\% C C H_{i}$ & $\begin{array}{c}0.879 \\
(0.523) \\
{[0.329]}\end{array}$ & $\begin{array}{c}0.054 \\
(0.309)\end{array}$ & $\begin{array}{l}-0.090 \\
(0.121) \\
{[-0.033]}\end{array}$ & $\begin{array}{l}-0.036 \\
(0.050)\end{array}$ \\
\hline$C_{i}, \% C C H_{i}$, and $C H / P_{i}$ & $\begin{array}{l}1.106 \\
(0.460) \\
{[0.409]}\end{array}$ & $\begin{array}{c}0.331 \\
(0.254)\end{array}$ & $\begin{array}{l}-0.085 \\
(0.118) \\
{[-0.031]}\end{array}$ & $\begin{array}{l}-0.034 \\
(0.048)\end{array}$ \\
\hline$C_{i}$ only & $\begin{array}{c}0.761 \\
(0.543) \\
{[0.285]}\end{array}$ & $\begin{array}{l}-0.093 \\
(0.324)\end{array}$ & $\begin{array}{c}-0.133 \\
(0.130) \\
{[-0.049]}\end{array}$ & $\begin{array}{l}-0.056 \\
(0.054)\end{array}$ \\
\hline$C_{i} \times D_{i}$ & $\begin{array}{c}1.333 \\
(0.516) \\
{[0.478]}\end{array}$ & $\begin{array}{c}2.572 \\
(2.442)\end{array}$ & $\begin{array}{l}-0.121 \\
(0.262) \\
{[-0.044]}\end{array}$ & $\begin{array}{l}-0.395 \\
(0.169)\end{array}$ \\
\hline None & $\begin{array}{c}1.224 \\
(0.542) \\
{[0.446]}\end{array}$ & $\begin{array}{l}\cdots \\
\cdots\end{array}$ & $\begin{array}{l}-0.094 \\
(0.301) \\
{[-0.034]}\end{array}$ & $\begin{array}{l}\cdots \\
\cdots\end{array}$ \\
\hline
\end{tabular}

Notes:

(1) Sample is taken from counties in the NLS-72 which had a population of greater than 250,000 in 1980.

(2) All equations control for parents' education and income levels and SES, whether father is a blue-collar worker, county population, gender and race.

(3) The Instrument " $\% \mathrm{CCH}_{i}$ " refers to the percent of the county which reports they are Catholic church members, and "CH/P ${ }_{i}$ " to Catholic schools per person in the county. 